\title{
Christopher Steimle
}

\section{Religion im römischen Thessaloniki}

\author{
Sakraltopographie, Kult und Gesellschaft 168 v. Chr. - 324 n. Chr.
}

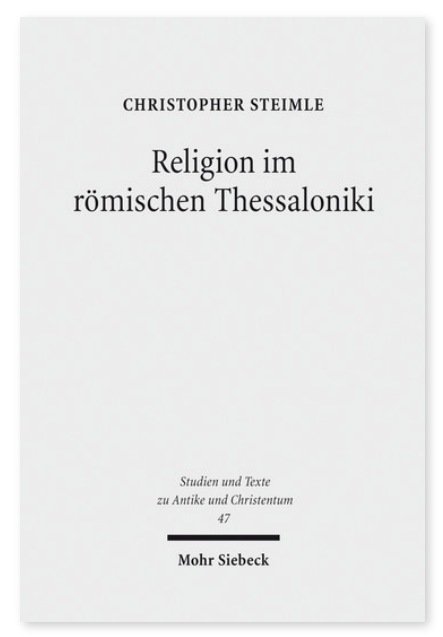

2008. XI, 240 Seiten. STAC 47

ISBN 978-3-16-151346-6

DOI 10.1628/978-3-16-151346-6

eBook PDF 79,00€

ISBN 978-3-16-149410-9

fadengeheftete Broschur 79,00€
Christopher Steimle untersucht die Religionen und Kulte in Thessaloniki während der Zeit der römischen Republik und der Kaiserzeit. Dabei gilt sein Hauptinteresse den Veränderungen, die als Folge der Einbindung Makedoniens in das römische Provinzsystem erkennbar werden und die Ergebnis von Austauschprozessen zwischen Reichszentrum und Provinz, zwischen Thessaloniki und anderen städtischen oder religiösen Zentren innerhalb Makedoniens sowie auch zwischen Makedonien und seinen benachbarten Regionen sind. Quellen sind vorrangig epigraphische und archäologische Zeugnisse, wobei für letztere in weiten Bereichen eine kritische Neuvorlage geleistet wird.

Indem die Vielfalt reichsweiter Beziehungen sowie die Bedingungen von Angebot und Auswahl von Religion durch die Rezipienten besonders berücksichtigt werden, wird auch ein neuartiges Erklärungsmodell für die lokale Religionsgeschichte gewonnen. Besonderes Gewicht liegt auf der Darstellung der Transportwege und -mechanismen religiöser Diffusion ebenso wie der beteiligten Personen (etwa Soldaten, Beamte, Händler) und Medien (Literatur, Inschriften, Münzen). Viele der Kulte der Stadt werden hier erstmals im Hinblick auf sozialgeschichtliche Aspekte betrachtet. Provinzialrömische Religion erweist sich dabei in Thessaloniki nicht als Importgut, welches vom Zentrum Rom aus die Provinzen durchdrungen hat, sondern als am Ort entstandene - und dabei größtenteils aktiv gestaltete - Reaktion auf die sich ständig wandelnden Bedingungen, denen die Stadt gegenüberstand.

Christopher Steimle Geboren 1967; Studium der Klassischen Archäologie in Tübingen und Heidelberg; 2005 Promotion.

Jetzt bestellen:

https://mohrsiebeck.com/buch/religion-im-roemischen-thessaloniki-9783161513466?no_cache=1

order@mohrsiebeck.com

Telefon: +49 (0)7071-923-17

Telefax: $+49(0) 7071-51104$ 